\title{
ĐÁNH GIÁ KẾT QUẢ SỚM \\ PHẪU THUẬT THAY VAN HAI LÁ CƠ HỌC ĐỜ THUẦN TẠI TRUNG TÂM TIM MẠCH BỆHH VIỆN E
}

\author{
Nguyễn Hồng Hạh, Nguyễn Công Hưu, Đố Anh Tiến,Nguyễn Bằng Việt, Phan Thảo Nguyên,

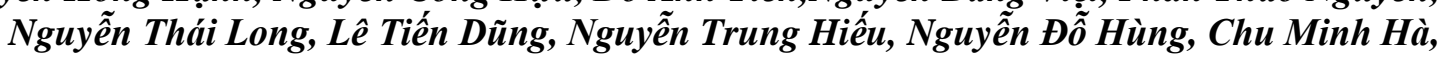 \\ Tạ Mạnh Cừ̀ng* Lê Ngọc Thành
}

\begin{abstract}
TÓM TẮT
Mục tiêu: Nhận xét tổn thương tim trong mổ ở bệnh nhẩn phẫu thuật thay van hai lá (VHL) cơ học đơn thuần tại trung tâm Tim mạch bệnh viện $\mathrm{E}$. Đánh giá kết quả sớm sau phẫu thuật thay VHL cơ học đơn thuần. Đối tượng: Toàn bộ bệnh nhân được thay VHL cơ học đơn thuần tại TTTM bệnh viện E trong 1 năm từ $1 / 2010$ đến $1 / 2011$, gồm 111 bệnh nhân. Phương pháp: Thiết kế nghiên cứu can thiệp lâm sàng không đối chứng. Các bệnh nhân đều được mổ thay $\mathrm{VHL}$ có bảo tồn dây chẳng lá sau. Kết quả và kết luận: Tổn thương VHL chủ yếu là bệnh van tim do thấp van đã vôi hóa. Tỉ lệ huyết khối nhĩ trái ở nhóm HHL cao hơn nhiều so với nhóm $\mathrm{HHoHL}$ và nhóm HHoHL cao hơn nhiều so với nhóm HoHL. Tử vong sau mổ do vỡ thất trái $(1,8 \%)$ gặp ở bệnh nhân có VHL và tổ chức dưới van vôi thành cục. Biến chứng và điều trị sau mổ chủ yếu liên quan đến thời gian kẹp động mạch chủ và tuần hoàn ngoài cơ thể.
\end{abstract}

\section{SUMMARY}

Early results after single mechanical mitral valve replacement in cardiovascular center $-\mathbf{E}$ hospital. Objectives: To investigate the cardiac lesions in patients who had the single mechanical mitral valve replacement at cardiovascular center - E hospital and assess the short-term results after operation. Patients: All 111 patients operated with single mechanical mitral valve replacement in cardiovascular center - E hospital during 1 year from Jan/2010 to Jan/2011. Method: clinical intervention study, without control. All of the patients were preservation of the basal chordae of the posterior leaflet. Results and conclusions: The predominant lesion of the mitral valve was rheumatic heart valve disease with calcification. Hospital mortality was $1,8 \%$ due to left ventricular rupture in patients who had severe calcification of mitral valve. Postoperative complications and treatment were mainly influenced by the duration of aortic crossclamp time and cardiopulmonary bypass.

\section{ĐẠTT VẤN ĐỀ}

Thấp tim và bệnh van tim do thấp là bệnh tim thường gặp nhất ở các nước đang phát triển, trong đó có Việt Nam. ${ }^{8}$ Tổn thương thường gặp nhất trong bệnh van tim do thấp là van hai lá (VHL), trong đó nhiều bệnh

\footnotetext{
*Viện Tim mạch Bạch Mai
}

nhân cần được phẫu thuật thay van. Ở Việt Nam, phẫu thuật thay van hai lá được thực hiện lần đầu tiên năm 1971 tại bệnh viện Việt Đức, ${ }^{1,2}$ cho đến nay có một số trung tâm mổ tim trong cả nước đã tiến hành phẫu thuật này nhưng vẫn chưa có nhiều nghiên cứu về kết quả sớm sau phẫu thuật thay $\mathrm{VHL}$ và các yếu tố ảnh hưởng đến các biến chứng sau mổ. Vì vậy, chúng tôi tiển hành đề tài "đánh giá kết quả sớm phẫu thuật thay van hai lá cơ học đơn thuần tại trung tâm Tim mạch - bệnh viện $E$ " nhằm 2 mục tiêu: 1. Nhận xét tổn thương tim trong mổ ở bệnh nhân phẫu thuật thay van hai lá co học đơn thuần. 2. Đánh giá kết quả sớm sau phẫu thuật thay van hai lá co' học.

\section{I. ĐỐI TƯợNG VÀ PHƯƠNG PHÁP NGHIÊN CÚU 2.1. Đối tượng nghiên cứu}

Tiêu chuẩn chon bệnh nhân: Toàn bộ các bệnh nhân được thay VHL cơ học đơn thuần tại TTTM bệnh viện $\mathrm{E}$ trong thời gian 1 năm từ $23 / 1 / 2010$ đến 19/1/2011, đồng ý tham gia nghiên cứu.

Tiêu chuẩn loại trù̀: Các bệnh nhân có kèm theo bệnh lí van động mạch chủ, động mạch vành cần phải can thiệp, hoặc có kèm theo bệnh tim bẩm sinh.

\subsection{Phương pháp nghiên cứu}

Sử dụng thiết kế nghiên cứu can thiệp lâm sàng không đối chứng. Mẫu nghiên cứu được chọn chủ đích, gồm tất cả 111 bệnh nhân có đủ tiêu chuẩn lựa chọn và tiêu chuẩn loại trừ như trên, trong giai đoạn nghiên cứu. Các bệnh nhân đều được mổ thay van hai lá theo phương pháp bảo tồn dây chằng lá sau.

Các kĩ thuật thu thập thông tin bao gồm: phỏng vấn bệnh nhân, khám lâm sàng, siêu âm tim, chụp mạch vành, quan sát tổn thương tim và các thông số sinh tồn trong và sau mổ, phát hiện các biến chứng trong thời gian hồi sức.

Chỉ định thay VHL cơ học theo khuyến cáo của ACC/AHA 2008., ${ }^{3,45}$

Trong số 111 bệnh nhân có chỉ định thay VHL cơ học đơn thuần tại TTTM bệnh viện $\mathrm{E}$, chúng tôi chia làm 3 nhóm bệnh có sinh lí bệnh khác nhau để so sánh 1 số đặc điểm: Nhóm 1: Hẹp van hai lá (HHL) là chính, hở van hai lá $(\mathrm{HoHL}) \leq 1 / 4$, tạm gọi là nhóm HHL; nhóm 2: hẹp hở van hai lá (HHoHL) và nhóm 3 là HoHL đơn thuần. 


\subsection{Phương pháp xử lí số liệu}

Kết quả nghiên cứu được phân tích và trình bày theo bảng tần số, bảng 2 biến số. Test kiểm định giả thuyết được sử dụng và so sánh kết quả giữa các nhóm bệnh nhân. Giá trị $\mathrm{p}$ được sử dụng và khác biệt có ý nghĩa thống kê khi $\mathrm{p}<0,05$.
Phân tích mối liên quan giữa 2 biến định lượng, dùng hệ số và phương trình tương quan tuyến tính.

Khi yếu tố nguy cơ là một biến định lượng, dùng phương pháp cut-off từng mức để tìm ngưỡng tối ưu cho chẩn đoán; xác định giá trị chẩn đoán của ngưỡng này này chúng tôi dùng độ nhạy và độ đặc hiệu.

\section{KẾT QUẢ NGHIÊN CÚU}

Mẫu nghiên cứu gồm 111 bệnh nhân với độ tuổi trung bình là 45,73 $\pm 10,95$

\section{1. Đặc điểm tổn thương tim và kĩ thuật mổ \\ Màng ngoài tim}

Trong tổng số 111 bệnh nhân của chúng tôi có 13 bệnh nhân có màng ngoài tim bị dính, chiếm tỉ lệ $11,7 \%$; trong đó có 10 bệnh nhân có tiền sử mổ tách VHL. Như vậy, $100 \%$ bệnh nhân có tiền sử mổ tách VHL có màng ngoài tim bị dính, đặc biệt có 3 bệnh nhân màng ngoài tim dính không rõ nguyên nhân (3\%).

Đặc điểm van hai lá

\section{Bảng 1. Đặc điểm tổn thương van hai lá}

\begin{tabular}{lll}
\hline Đặc điểm & n & \% \\
\hline Vôi & 90 & 81,1 \\
Vôi + đứt dây chằng & 1 & 0,9 \\
Vôi + sùi, mủn & 1 & 0,9 \\
Đứt dây chằng & 3 & 2,7 \\
Đứt dây chằng + sùi, mủn & 2 & 1,8 \\
Dày, co rút & 11 & 9,9 \\
Dày, co rút + thủng van & 1 & 0,9 \\
Sa van & 1 & 0,9 \\
Dãn vòng van & 1 & 0,9 \\
Tổng & 111 & 100 \\
\hline
\end{tabular}

Tổn thương VHL chủ yếu là bệnh van tim do thấp với đặc điểm van vôi và co rút, trong đó tổn thương osler gặp ở $4(3,6 \%)$ bệnh nhân với 1 bệnh nhân thủng van. Có 1 bệnh nhân sa van và 1 bệnh nhân dãn vòng van hai lá.

\section{Huyết khối trong tim}

Có 23 bệnh nhân có huyết khối trong tim, chiếm tỉ lệ 20,7\%; trong đó 47,8\% là huyết khối nhĩ trái; 47,8\% là huyết khối tiểu nhĩ trái và chỉ có $4,3 \%$ là có huyết khối cả nhĩ trái và tiểu nhĩ trái.

Phân tích tỉ lệ huyết khối theo từng nhóm bệnh chúng tôi thu được kết quả sau:

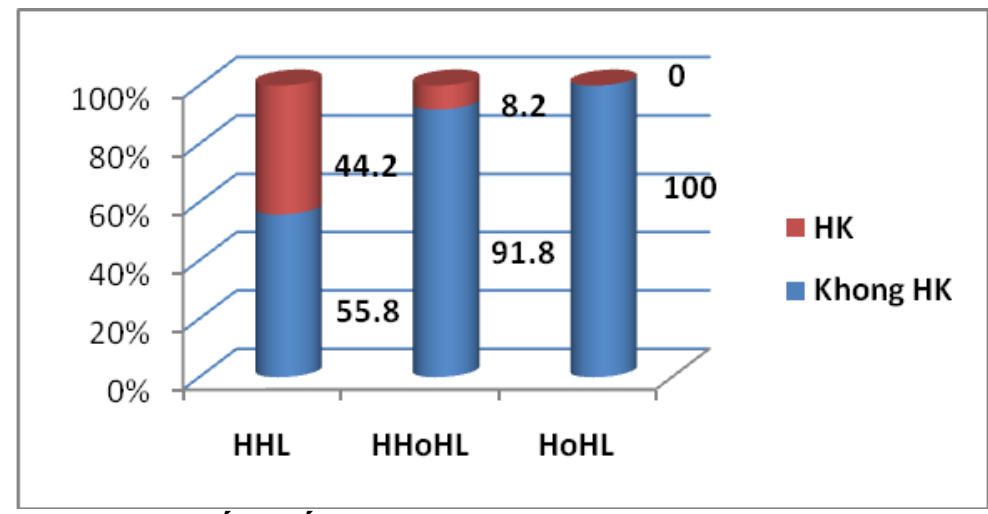

Đồ thị 1. Tỉ lệ huyết khối theo 3 nhóm bệnh van hai lá

Tỉ lệ HK ở nhóm HHL là 44,2\%, cao hơn nhóm HHoHL (8,2\%) và nhóm HoHL đon thuần không có bệnh nhân nào có huyết khối. Sự khác biệt này rất có ý nghĩa thống kê với $p=0,0001$. 


\section{Khâu buộc chân tiểu nhĩ trái}

Có 49 bệnh nhân được khâu buộc chân tiểu nhĩ trái, chiếm tỉ lệ 44\%; trong đó tất cả các bệnh nhân (n=23) có huyết khối trong tim đều được khâu buộc chân tiểu nhĩ trái; và 26 bệnh nhân không có $\mathrm{HK}$ vẫn được tiến hành kĩ thuật này. Có 3 bệnh nhân $(2,7 \%)$ được phẫu thuật cuộn bớt nhĩ trái do nhĩ trái dãn quá to.

\section{Tạo hinh VBL}

Có 34 (30,6\%) bệnh nhân HoBL $\geq 2 / 4$ được tạo hình van ba lá, 100\% theo phương pháp De Vega.

Số van nhân tạo

số van $29(37 \%)$; số $27(27 \%)$, số $31(21 \%)$ và số van 33 (15\%), có tương quan thuận với BSA (diện tích bề mặt cơ thể tính theo công thức Dubois), $\mathrm{p}=0,02$.

\section{Một số đặc điểm của kĩ thuật mổ theo nhóm bệnh}

Bảng 2. Tuần hoàn ngoài cơ thể và điều trị sau mổ

\begin{tabular}{llllll}
\hline & $\begin{array}{l}\text { HHL } \\
(\mathbf{n = 4 3})\end{array}$ & $\begin{array}{l}\text { HHoHL } \\
(\mathbf{n = 4 9 )}\end{array}$ & $\begin{array}{l}\text { HoHL } \\
(\mathbf{n = 1 9 )}\end{array}$ & $\begin{array}{l}\text { Chung } \\
(\mathbf{n = 1 1 1})\end{array}$ & $\mathbf{p}$ \\
\hline T kẹp chủ (phút) & $77,9 \pm 26,5$ & $71,2 \pm 13,5$ & $79,2 \pm 27,6$ & $75,2 \pm 22$ & 0,497 \\
T CPB (phút) & $99,6 \pm 29,5$ & $91,2 \pm 18,4$ & $102,7 \pm 33,3$ & $96,5 \pm 26,2$ & $\mathbf{0 , 0 2 6}$ \\
T thở máy (giờ) & $7,4 \pm 9,0$ & $10,9 \pm 26,8$ & $6,0 \pm 6,6$ & $8,7 \pm 18,9$ & $\mathbf{0 , 0 0 0 1}$ \\
T nằm viện (ngày) & $18,5 \pm 6,15$ & $20,27 \pm 9,51$ & $20,8 \pm 6,4$ & $19,68 \pm 7,8$ & 0,46 \\
\hline
\end{tabular}

Như vậy, thời gian kẹp chủ và thời gian nằm viện tương tự nhau ở 3 nhóm bệnh HHL, HHoHL và HoHL; nhưng thời gian chay tuần hoàn ngoài co thể và thời gian thở máy khác biệt có ý nghĩa thống kê ở 3 nhóm bệnh này $(p<0,05)$ : nhóm HoHL có thời gian chạy máy dài nhất nhưng thời gian thở máy ngắn nhất; trong khi nhóm HHoHL lại ngược lại: thời gian chạy máy ngắn nhất nhưng thời gian thở máy lại dài nhất.

Phân tích mối tương quan giữa thời gian kẹp chủ và thời gian thở máy, thời gian chạy $\mathrm{CPB}$ và thời gian thở máy, thời gian kẹp chủ và thời gian nằm viện, thời gian chạy $\mathrm{CPB}$ và thời gian nằm viện: không có mối tương quan giữa từng cặp 2 đại lượng này với $\mathrm{r}_{1}=0,14, \mathrm{r}_{2}=0,18, \mathrm{r}_{3}=0,14, \mathrm{r}_{4}=0,11$.

\subsection{Kết quả sớm phẫu thuật thay van hai lá cơ học đơn thuần}

\section{Các biến chứng}

Tử vong: Có 2 bệnh nhân tử vong do vỡ thất trái, chiếm tỉ lệ 1,8\%. 2 bệnh nhân đều có đặc điểm bộ máy van hai lá và tổ chức dưới van vôi hóa thành cục. Không có bệnh nhân nào tử vong do các biến chứng khác.

Chảy máu: 24 bệnh nhân (22\%) phải truyền máu sau mổ; 1 bệnh nhân $(0,9 \%)$ xuất huyết não; 1 bệnh nhân $(0,9 \%)$ đái máu và 1 bệnh nhân $(0,9 \%)$ chảy máu dạ dày; không có trường hợp nào chảy máu phải mổ lại.

Phân tích một số yếu tố có thể ảnh hưởng lên biến chứng chảy máu, chúng tôi thu được kết quả sau:

Bảng 3. Ảnh hưởng của 1 số yếu tố lên biến chứng chảy máu

\begin{tabular}{llll}
\hline & $\begin{array}{l}\text { Không chảy máu } \\
(\mathbf{n}=\mathbf{8 5})\end{array}$ & $\begin{array}{l}\text { Chảy máu } \\
(\mathbf{n = 2 4})\end{array}$ & $\mathbf{p}$ \\
\hline Tuổi & $44,95 \pm 10,9$ & $47,04 \pm 11,3$ & 0,414 \\
T kẹp chủ (phút) & $72,8 \pm 21,1$ & $84,5 \pm 23,8$ & $\mathbf{0 , 0 2 2}$ \\
T CPB (phút) & $94,5 \pm 24,7$ & $104,7 \pm 30,4$ & 0,092 \\
T thở máy (giờ) & $7,14 \pm 14,36$ & $14,38 \pm 29,58$ & 0,097 \\
\hline
\end{tabular}

Như vậy, chỉ có thời gian kẹp chủ ảnh hưởng lên biến chứng chảy máu sau mổ $(\mathrm{p}<0,05)$, thời gian kẹp chủ càng dài thì nguy cơ chảy máu càng lớn. Dùng phương pháp cut-off để đưa ra 1 ngưỡng tối ưu cho chẩn đoán, chúng tôi có kết quả: thời gian kẹp chủ $\geq 77$ phút thì có nguy cơ chảy máu sau mổ với độ nhạy là $58,0 \%$, độ đặc hiệu là $66 \%$.

Nhiếm trùng: 39 bệnh nhân $(35,8 \%)$ có sốt; trong đó chỉ có 1 bệnh nhân $(0,9 \%)$ nhiễm trùng xương ức. Không thấy mối liên quan giữa tuổi, thời gian kẹp chủ, thời gian chạy $\mathrm{CPB}$, thời gian thở máy với biến chứng sốt sau mồ.

Các biến chứng khác: 1 bệnh nhân $((0,9 \%)$ bị loạn thần.

\section{Thuốc vận mạch}

109 bệnh nhân về đến hồi sức thì có 70 bệnh nhân $(64,2 \%)$ phải dùng 1 thuốc vận mạch; có 22 bệnh nhân $(20,2 \%)$ dùng $\geq 2$ thuốc vận mạch; chỉ có 17 bệnh nhân $(15,6 \%)$ không phải dùng thuốc vận mạch. 
Phân tích sự ảnh hưởng của thời gian kẹp chủ, thời gian chạy $\mathrm{CPB}$, thời gian thở máy và $\mathrm{Dd}, \mathrm{EF}$ trước mổ lên việc dùng thuốc vận mạch, chúng tôi có kết quả sau:

Bảng 4. Ảnh hưởng của 1 số yếu tố lên việc dùng thuốc trợ tim

\begin{tabular}{lllll}
\hline & $\begin{array}{l}\text { Ko thuốc VM } \\
(\mathbf{n = 1 7 )}\end{array}$ & $\begin{array}{l}\mathbf{1} \text { thuốc VM } \\
(\mathbf{n = 7 0 )}\end{array}$ & $\begin{array}{l}\mathbf{2} \text { thuốc VM } \\
(\mathbf{n = 2 2})\end{array}$ & $\mathbf{p}$ \\
\hline Tuổi & $41,35 \pm 9,4$ & $45,39 \pm 11,5$ & $48,41 \pm 11,0$ & 0,122 \\
T kẹp chủ (phút) & $75,8 \pm 24,6$ & $73,6 \pm 21,3$ & $80,4 \pm 23,3$ & 0,497 \\
T CPB (phút) & $91,2 \pm 26$ & $93,8 \pm 23,5$ & $110,3 \pm 6,7$ & $\mathbf{0 , 0 2 6}$ \\
T thở máy (giờ) & $3,1 \pm 1,44$ & $5,5 \pm 4,6$ & $23,5 \pm 38,3$ & $\mathbf{0 , 0 0 0 1}$ \\
Dd (mm) & $52,5 \pm 7,9$ & $51,7 \pm 8,5$ & $52,5 \pm 10,1$ & 0,9 \\
EF (\%) & $58,6 \pm 6,7$ & $59,7 \pm 7,4$ & $58,0 \pm 8,2$ & 0,6 \\
\hline
\end{tabular}

Thời gian chạy tuần hoàn ngoài cơ thể và thời gian thở máy khác biệt rất có ý nghĩa thống kê ở 3 nhóm: không dùng thuốc vận mạch, 1 thuốc và $\geq 2$ thuốc vận mạch $(\mathrm{p}<0,05)$ : thời gian chạy $C P B$ càng dài thì càng phải dùng nhiều thuốc vận mach và thời gian thở máy càng kéo dài. Dùng phương pháp cut-off để đưa ra 1 ngưỡng tối ưu cho chẩn đoán, chúng tôi có kết quả: thời gian chạy $\mathrm{CPB} \geq 99$ phút thì có nguy cơ phải dùng 2 thuốc vận mạch sau mổ với độ nhạy là 14/22=63,6\%, độ đặc hiệu là 59/87=67,8\%.

\section{BÀN LUẬN \\ 4.1. Đặc điểm tổn thương tim trong mổ và kĩ thuật mổ}

Kết quả nghiên cứu của chúng tôi có $11,7 \%$ bệnh nhân có màng ngoài tim bị dính; trong đó có 3 bệnh nhân màng ngoài tim dính không rõ nguyên nhân. Đặc điểm VHL trong nghiên cứu của chúng tôi, chủ yếu là tổn thương van hai lá do thấp với tỉ lệ vôi hóa $81,1 \%$, phù hợp với mô hình bệnh van hai lá ở các nước đang phát triển; tỉ lệ osler cũ $3,6 \%$, đứt dây chằng đơn thuần $2,7 \%$. Một kết quả đáng lưu ý là gần một nửa số bệnh nhân $\mathrm{HHL}$ đơn thuần $(44,2 \%)$ có huyết khối, cao hơn hẳn nhóm HHoHL $(8,2 \%)$ và không có bệnh nhân nào HoHL đơn thuần có huyết khối, sự khác biệt rất có ý nghĩa thống kê với $\mathrm{p}=0,0001$. Kết quả này ủng hộ giả thuyết cho rằng dòng hơ VHL phut ngược lại nhĩ trái có tác dụng rủa nhĩ trái nên khó hình thành cục máu đông trong nhĩ.

Trong nghiên cứu của chúng tôi có $44 \%$ bệnh nhân được khâu buộc chân TNT và $2,7 \%$ được cuộn bớt nhĩ trái, trong nghiên cứu của Nguyễn Xuân Thành thực hiện tại bệnh viện Việt Đức là $1,8 \%{ }^{2}$, Ko Bando là (khâu chân TNT $51 \%$, cuộn bớt nhĩ trái $18 \%)^{6}$

Số van nhân tạo có tương quan thuận với BSA, tỉ lệ dùng số 29 cao nhất, tương tự kết quả của Nguyễn Xuân Thành làm ở bệnh viện Việt Đức. ${ }^{2}$ Kết quả này ủng hộ giả thuyết kích thước VHL của người Việt Nam phù hợp phần lớn với số van 29.

\subsection{Kết quả sớm phẫu thuật thay van hai lá co học đơn thuần}

Trong thời gian 1 năm đầu thành lập, từ 23/1/2010 đến 19/1/2011, Trung tâm Tim mạch bệnh viện $\mathrm{E}$ mổ được 641 bệnh nhân, trong đó có 540 ca mổ có tim phổi máy. 182 trường hợp được thay van tim, chiếm tỉ lệ $28,4 \%$ tổng số bệnh nhân mổ và chiếm $33,7 \%$ trường hợp mổ tim có tuần hoàn ngoài cơ thể. Có 111 bệnh nhân được thay VHL cơ học đơn thuần. Số lượng bệnh nhân mổ của trung tâm Tim mạch bệnh viện $\mathrm{E}$ tương đương các trung tâm mổ tim lớn khác ở trong nước.

Tỉ lệ tử vong của chúng tôi là $1,8 \%$, bệnh viện Việt Đức là $1,8 \%{ }^{2}$ và viện Tim Hà Nội là $2,5 \%^{1}$ và các nghiên cứu khác trên thế giới là $3-9 \% \%^{5,6,7}$. Bệnh nhân tử vong của chúng tôi đều do biến chứng vỡ thất trái trên bệnh nhân có van hai lá và bộ máy dưới van vôi thành cục. Như vậy, có thể giả thuyết rằng van hai lá và bộ máy dưới van vôi thành cục, là yếu tố nguy cơ xấu cho kết quả phẫu thuật thay van.

$2 \%$ bệnh nhân phải truyền máu sau mổ, nhưng không có bệnh nhân nào chảy máu phải mổ lại. Một kết quả đáng luu ý: thời gian kẹp chủ dài $(\geq 77$ phút) là môt yếu tố nguy cơ của chảy máu sau mồ.

Tỉ lệ nhiễm trùng xương ức thấp $(0,9 \%)$.

Tỉ lệ phải dùng thuốc vận mạch sau mổ của chúng tôi tương tự nghiên cứu của Nguyễn Xuân Thành làm ở bệnh viện Việt Đức và cao hơn Đặng Hanh Sơn làm ở viện Tim Hà Nội. ${ }^{1,2}$ Một kết quả đáng luu ý khác: thời gian chạy $C P B$ dài $(\geq 99$ phút) là một yếu tố nguy co của việc phải dùng $\geq 2$ thuốc vận mạch sau mồ. Kết quả này ủng hộ giả thuyết tuần hoàn ngoài co thể có ảnh hưởng đáng kể lên chức năng tim. 


\section{KẾT LUẬN}

5.1. Tổn thương VHL chủ yếu là bệnh van tim do thấp van đã vôi hóa. Tỉ lệ huyết khối nhĩ trái ở nhóm HHL cao hơn nhiều so với nhóm HHoHL và nhóm HHoHL cao hơn nhiều so với nhóm HoHL.

5.2. Tử vong sau mổ do vỡ thất trái gặp ở bệnh nhân có VHL và tổ chức dưới van vôi thành cục. Biến chứng và điều trị sau mổ chủ yếu liên quan đến thời gian kẹp động mạch chủ và tuần hoàn ngoài cơ thể.

\section{TÀI LIỆU THAM KHẢO}

1. Đặng Hanh Sơn. Nghiên cứu kết quả phẫu thuật thay van hai lá bằng van cơ học Sorin tại bệnh viện Tim Hà Nội. Luận án tiến sĩ y học 2010;58-68.

2. Nguyễn Xuân Thành. Nghiên cứu đặc điểm lâm sàng, cận lâm sàng và kết quả phẫu thuật thay van hai lá có huyết khối nhĩ trái tại bệnh viện Việt Đức. Luận văn thạc sĩ y học 2010;61-68.

3. 2008 Focused update incorporated into the ACC/AHA 2006 guidelines for the management of patients with valvular heart disease. Circulation 2008;118(15):523-660.

4. ACC/AHA 2006 guidelines for the management of patients with valvular heart disease. Journal of the American College of Cardiology 2006;48(3):41-67.

5. Gudbjartsson T i, Aranki S i, Cohn L Hi. Mechanical/Bioprosthetic Mitral valve Replacement. Cardiac Surgery in the Adult. New York: McGrawHill, 2003:951-986.

6. Ko Bando, MD, Junjiro Kobayashi, MD, Mitsuhiro Hirata, MD et al. Early and late stroke after mitral valve replacement with a mechanical prosthesis: risk factor analysis of a 24-year experience. Thorac Cardiovasc Surg 2003;126:358-364.

7. Sameh I. Sersar, Ahmed A. Jamjoom. Left ventricular rupture post mitral valve replacement. Clinical Medicine: Cardiology 2009;3:101-113.

8. WHO Technical Report series. Rheumatic fever and rheumatic heart disease. Geneva 2004;3-7,73-80. 